\title{
Survey of management practices of dairy cows grazing kale in Canterbury
}

\author{
H.G JUDSON ${ }^{1}$ and G.R EDWARDS ${ }^{2}$ \\ ${ }^{I}$ Agricom, P.O Box 3761, Christchurch \\ ${ }^{2}$ Lincoln University, P.O Box 84, Lincoln University \\ gjudson@agricom.co.nz
}

\begin{abstract}
Many dairy cows, particularly in southern New Zealand have kale (Brassica olercaea) as a major component of their winter diet. Anecdotal evidence suggests variable results in cow body condition are achieved when kale is used as a component of the winter diet. A survey of crop yield, nutritive value and grazing management practices of kale crops was undertaken in Canterbury during winter 2007 to investigate possible causes of these variable results. Kale utilisation ranged from less than $40 \%$ to greater than $90 \%$ on kale yields that ranged from $5-17 \mathrm{t}$ DM. Nutritive value of kale was generally high (12 MJ $\mathrm{ME} / \mathrm{kg} \mathrm{DM}$ ) but diet ME declined as grazing residuals decreased due to the poorer quality of the lower stem. Two thirds of the herds consumed less than the targeted DM intake by more than $1 \mathrm{~kg} \mathrm{DM} / \mathrm{cow} /$ day. Inaccurate crop allocation was the likely cause of cows not achieving their targeted kale intakes.
\end{abstract}

Keywords: kale, utilisation, allowance, quality, dairy

\section{Introduction}

Regaining body condition lost through lactation is a common goal for many New Zealand dairy systems. Typically, cows are dried off at a body condition score of 4.5 or lower and it is desirable to have these animals at a score of 5.0 at calving. Cows in better condition have been shown to have a shorter post partum anoestrous interval (Burke et al. 2005) and may produce more milk solids over lactation (Holmes 2000).

Many dairy cows, particularly in southern New Zealand have kale (Brassica olercaea) as a major component of their winter diet. Kale crops lend themselves to such usage because they are able to produce a large quantity of high quality DM per unit area (Brown et al. 2007) and kale can be carried through the winter with less deterioration in nutritive value compared with other feeds. However, despite being the dominant winter forage for South Island dairy cows, little data exist on the utilisation of kale by cows although a figure of $70 \%$ is often quoted for dairy. This estimate for dairy utilisation is not based on any known scientific measurement. Studies with sheep (Gowers \& Armstrong 1994) showed utilisation could vary from $39-65 \%$ for six cultivars grazed collectively.

Anecdotal evidence suggests improvements in body condition of dairy cows fed mainly kale may in some situations not meet farmer expectations. The inability to reach body condition targets may result from (1) poor crop quality, (2) low DM intake through poor crop utilisation or slow adaptation to kale diets, or (3) low DM intake through inaccurate crop allocation. A survey of cows grazing kale in Canterbury was undertaken to investigate the likely cause of the variation from farmer expectation in cow performance over the winter period.

\section{Methods}

Data from irrigated $(\mathrm{n}=27)$ and non-irrigated $(\mathrm{n}=22)$ kale crops in Canterbury under dairy grazing were collected in June 2007. The survey captured data from 49 paddocks representing 31 different farms and four cultivars. Kale yields $(\mathrm{kg} \mathrm{DM} / \mathrm{ha})$ in each paddock were assessed by cutting to ground level a total area of $4 \mathrm{~m}^{2}\left(4 \mathrm{x} 1 \mathrm{~m}^{2}\right.$ quadrats) in the break due to be grazed the following day. Total fresh weight $(\mathrm{kg})$ was measured before a subsample of plants $(n=20)$ was dissected into stem and leaf (plus petiole) and each component weighed to determine proportional composition. Kale stems were subsequently cut into four equal lengths for measurements of quality. Sub-samples (approx. $500 \mathrm{~g}$ ) of leaf and each of the four stem components were oven dried at $65^{\circ} \mathrm{C}$ for $48 \mathrm{~h}$ to determine DM\%. Quality parameters of these components were determined using NIR analysis.

Post-grazing residual (kg DM/ha) was determined by collecting residual material from $4 \times 1 \mathrm{~m}^{2}$ quadrats in the break grazed the previous day. Post-grazing residual samples were not dissected. Dry matter percentage for residuals was determined after washing to remove soil and drying a representative sample at $65^{\circ} \mathrm{C}$ for $48 \mathrm{~h}$.

\section{Total yield ( $\mathrm{kg} D M / \mathrm{ha}$ ) was calculated as: \\ Yield $=($ fresh wt $(\mathrm{kg}) \times$ leaf $\%$ x leaf DM $\%+$ fresh wt ( $\mathrm{kg}) \times$ stem\% $\%$ stem DM\%) x 2500 where fresh weight was the total weight of the crop harvested from the $4 \mathrm{~m}^{2}$}

\section{Utilisation (\%) was calculated as: Utilisation $=$ \\ Pre-grazing DM yield - Post-grazing DM yield Pre-grazing DM yield x 100 \\ Where yield is measured in $\mathrm{kg} \mathrm{DM} / \mathrm{ha}$ \\ Details of crop husbandry and estimates of the amount of supplement offered to cows and their kale intake was}


Figure 1 Frequency distribution of yields for kale crops surveyed.

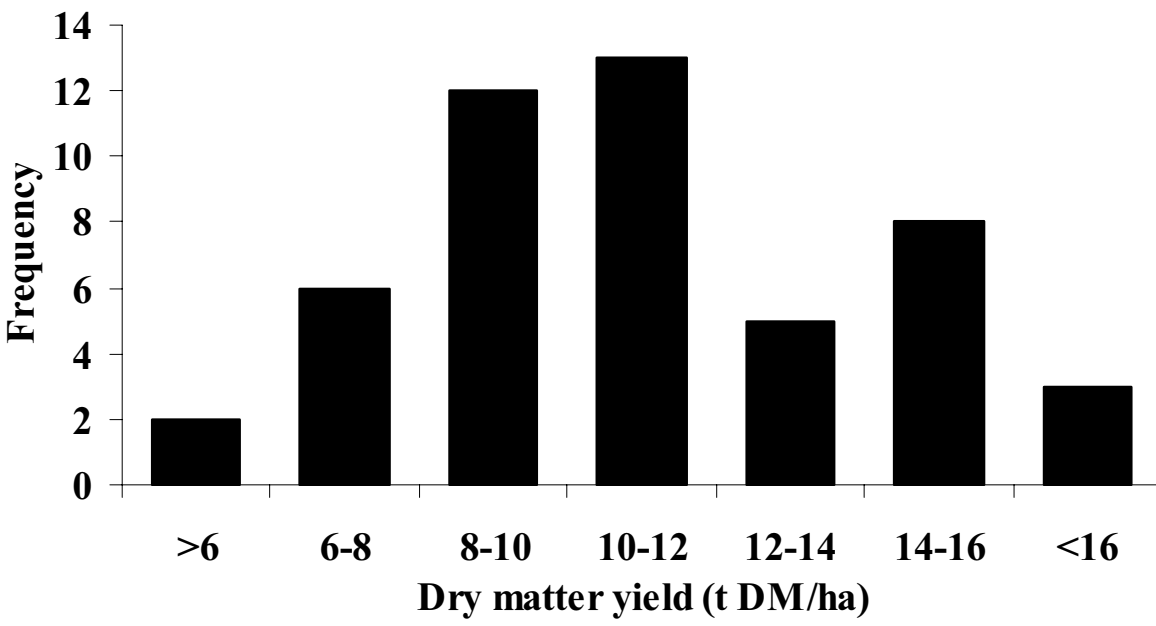

provided by the farmers involved in feeding the cows.

Descriptive statistics, comparisons and linear regressions were generated using Statistix 8. Means were compared using a two sample t-test.

\section{Results}

\section{Kale yields and composition}

Kale yields averaged 10.9 (SEM 0.41) t DM/ha and varied from 5.3 to 17.0 t DM (Fig. 1). Kale crops were grouped into intermediate-stem types (cv. Sovereign) $(n=39)$ and giant types (cv. Gruner, Burley and Rawara) $(\mathrm{n}=10)$. Kale type had a significant $(\mathrm{P}<0.01)$ effect on total yield with the intermediate-stem type in this survey averaging 9.9 (SEM 0.43) t DM and giant types averaging 13.6 (SEM 0.68) t DM.

Kale cultivars differed $(\mathrm{P}<0.01)$ in their composition (Table 1). For cultivars grouped as giant types, leaf and petiole accounted for $24 \%$ of the total DM yield with the balance as stem. For the intermediate stem cultivar, leaf and petiole accounted for $44 \%$ of total DM yield with the balance in stem. Quality of DM was also affected by both plant part and plant type. Quality was highest in leaf compared with stem and highest in the upper stem relative to the lower. The quality of giant type leaf material was similar to the intermediate-stem type leaf but stem quality was generally poorer in each comparable quarter. This difference in stem quality impacted on predicted diet ME. For example, cows eating $84 \%$ of the intermediate-stem type (leaving just the lower stem) would have a diet ME (12.0 MJ ME/kg DM) greater than an equivalent cow grazing $80 \%$ (leaving just the lower stem) of a giant type (11.0 MJ ME/ $\mathrm{kg} \mathrm{DM})$ (Table 1).

Across all cultivars the proportion of leaf was related to total DM yield (Fig. 2). Leaf percentage (\% of DM) declined by 3 percentage points for every extra tonne of DM grown. There was some evidence that the contribution of leaf proportion to total DM yield was less for giant types than for intermediate-stem type. However, when leaf yield was expressed per hectare there was no relationship with total DM yield and mean leaf yield was $3.9 \mathrm{t} / \mathrm{ha}$.

\section{Utilisation}

Generally, utilisation rates were high with a mean of $80 \%$ (Fig. 3.) In approximately $10 \%$ of observations,

Table 1 Composition (\% of total DM), quality (MJ ME/kg DM) and its impact on predicted diet ME from different kale types.

\begin{tabular}{lcccccc}
\hline & \multicolumn{3}{c}{ Intermediate-stem cultivar } & \multicolumn{3}{c}{ Giant-type cultivars } \\
\hline Plant Part & $\begin{array}{c}\text { \% of total } \\
\text { DM }\end{array}$ & $\begin{array}{c}\text { ME content } \\
\text { ME/kg DM }\end{array}$ & $\begin{array}{c}\text { Diet ME } \\
\text { MJ ME/kg DM }\end{array}$ & $\begin{array}{c}\text { \% of total } \\
\text { DM }\end{array}$ & $\begin{array}{c}\text { ME content } \\
\text { ME/kg DM }\end{array}$ & $\begin{array}{c}\text { Diet ME ME/kg DM } \\
\text { MJ ME }\end{array}$ \\
\hline Leaf & 44 & 12.9 & 12.9 & 24 & 12.7 & 12.7 \\
Upper stem & 11 & 12.4 & 12.8 & 17 & 11.6 & 12.2 \\
Upper mid & 14 & 11.6 & 12.6 & 19 & 9.7 & 11.4 \\
Lower mid & 15 & 9.4 & 12.0 & 20 & 9.8 & 11.0 \\
Lower & 16 & 8.6 & 11.5 & 20 & 6.6 & 10.1 \\
\hline
\end{tabular}

${ }^{1}$ Diet ME refers to the predicted average ME of the diet as more components are eaten. For example, a diet from an intermediate stem kale of leaf-only would be $12.9 \mathrm{MJ}$ ME/kg DM but a diet containing both leaf and the top half the stem would be 12.6 MJ ME/kg DM. 
Figure 2 Leaf proportion of medium stemmed $(O)$ and giant type $(\bullet)$ crops of different yields. Solid line and the equation represent the average for both types.

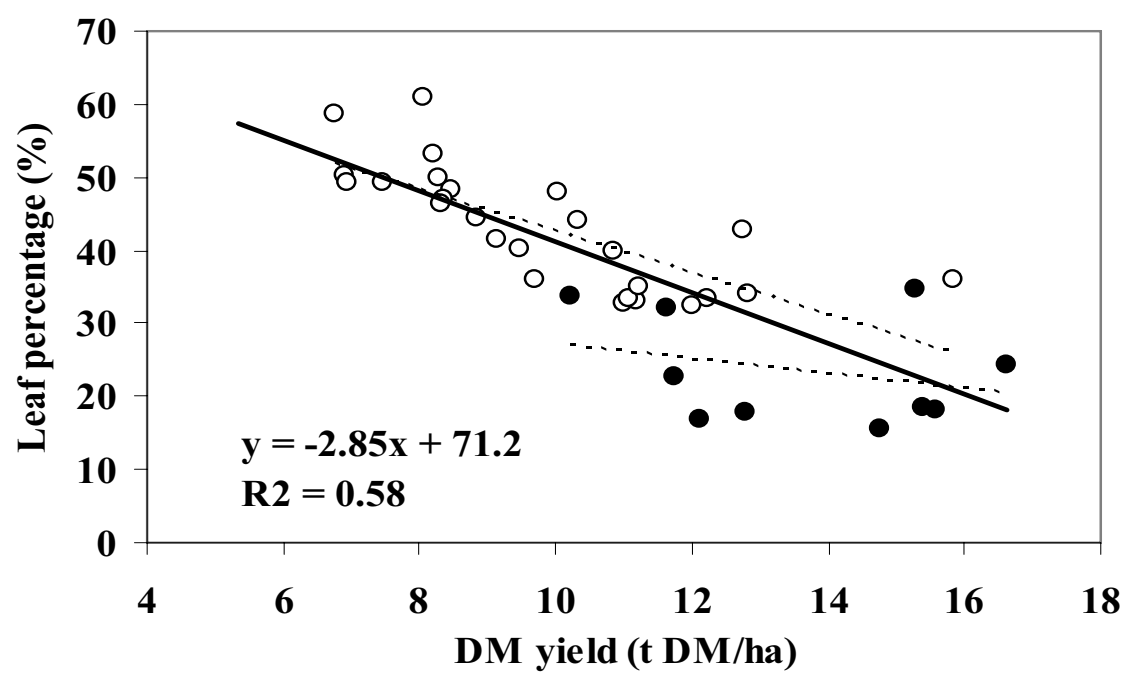

Figure 3 Frequency distribution of utilisation rates.

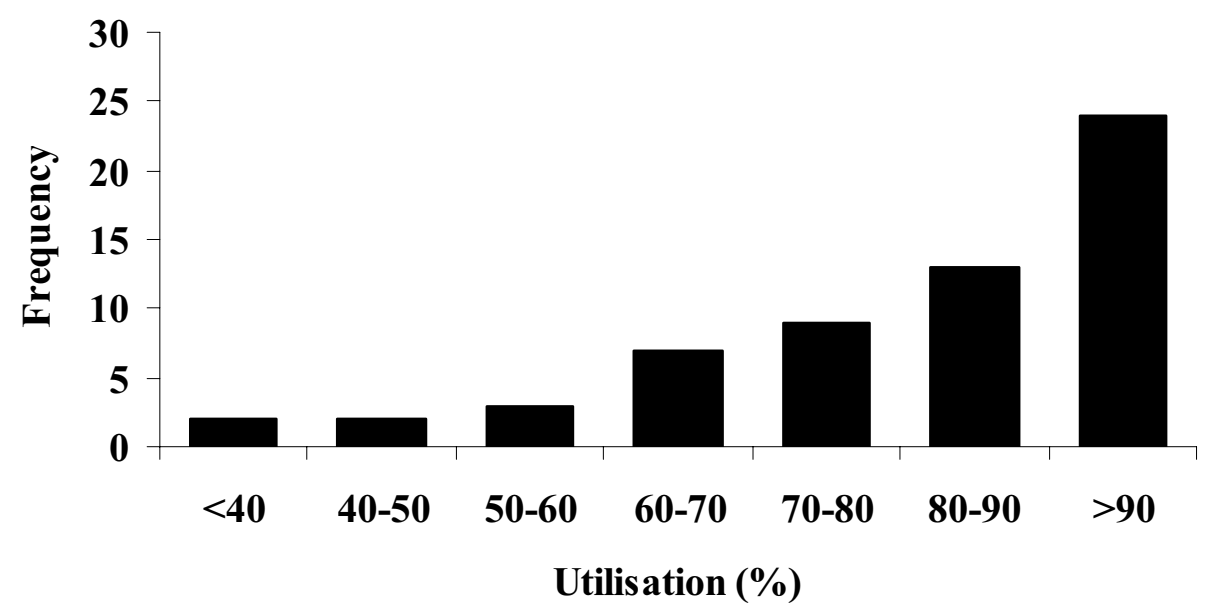

only half the crop or less was being utilised and in approximately $40 \%$ of cases more than $90 \%$ was being utilised. There was no relationship between kale type and utilisation. There was no apparent relationship between crop DM yield and utilisation for either the intermediate-stem cultivar or the giant types. Similarly, there was no relationship between break width (4-61 m), cow number per herd (96-960 cows) or DM\% on crop utilisation.

Apparent daily intake of kale ( $\mathrm{kg} \mathrm{DM} / \mathrm{cow} /$ day), estimated from paddock measurements (pre- and postgrazing mass, cow number and break size), was correlated with daily kale allowance (kg DM/cow/day) (Fig. 4). For every extra kg of DM offered to dairy cows, intake increased by $0.80 \mathrm{~kg} \mathrm{DM}$.
The utilisation of kale was related to the total daily allowance ( $\mathrm{kg} \mathrm{DM} / \mathrm{cow} /$ day) which included both kale and supplements (Fig. 5) although this relationship was weak probably reflecting accuracy around supplement allocation. As total daily allowance increased from 7 to $21 \mathrm{~kg} \mathrm{DM} / \mathrm{cow} /$ day, kale utilisation decreased from $87 \%$ to $55 \%$. High rates of kale utilisation were generally associated with low total daily allowances.

There were large differences between the target kale intake of cows as indicated by the farmer $(\mathrm{kg} \mathrm{DM} / \mathrm{cow} /$ day) and that estimated from the measurements made in this survey (Fig. 6). Two thirds of the herds in this survey appeared to miss their target kale intake by more than $1 \mathrm{~kg} \mathrm{DM} / \mathrm{cow} /$ day and some by $8 \mathrm{~kg} \mathrm{DM} /$ cow/ day. 
Figure 4 Relationship between daily kale allowance (kg DM/cow/day) and apparent kale intake (kg DM/cow/ day) (based on pre- and post-grazing residuals) for intermediate stem ( $\bigcirc$ ) and giant type (๑) crops.

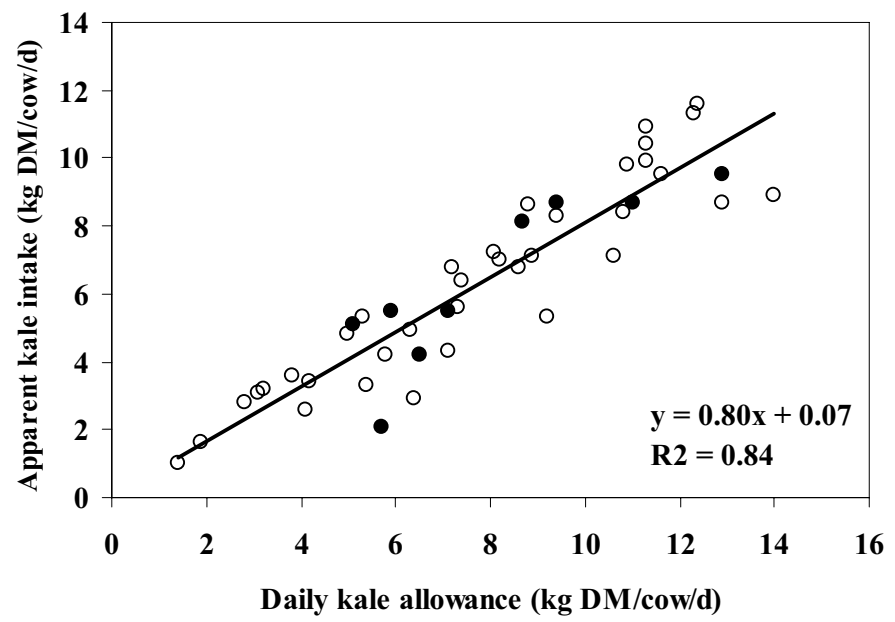

Figure 5 The effect of total daily allowance (kale plus supplements) on the utilisation of the kale crop.

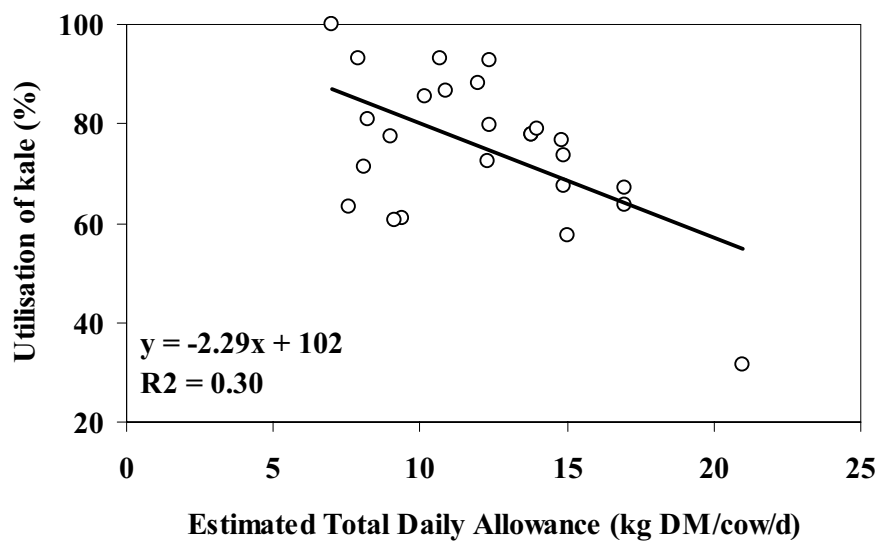

Figure 6 The target kale intake as indicated by farmers in the survey and apparent daily intake (based on preand post-grazing residuals). Line represents where target and apparent intakes agree. Data points below the line represent cows eating less than targeted.

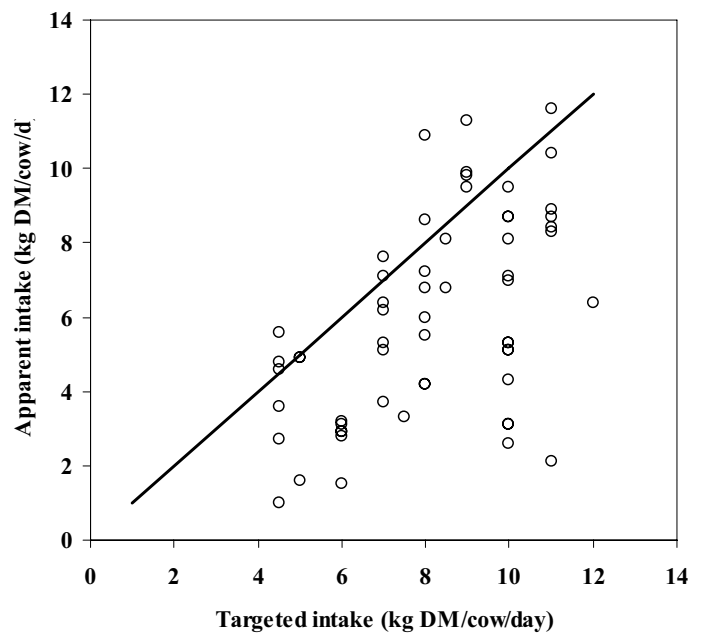




\section{Discussion}

\section{Yield}

Kale yield appeared normally distributed (Fig. 1) and is largely considered a function of soil fertility and environment (Beare et al. 2006). The growing season during the year of the survey was cool and average yields were probably reduced by up to $2 \mathrm{t} \mathrm{DM} / \mathrm{ha}$ (PGG Wrightson Seeds, unpublished data). In this survey, giant types generally produced higher yields than the intermediate stem cultivar but more of this yield was associated with poorer quality stem. The difference in yield may have been less extreme if the sample size of the medium stemmed and giant types had been more similar.

Although the proportion of leaf decreased as total yield increased the mean weight of leaf per hectare (3.9 t DM/ ha) was relatively constant across a range of yields. Some intermediate stem crops held up to $5.7 \mathrm{t} \mathrm{DM}$ of leaf but large kale yields were primarily achieved through increased stem production. The mean weight of leaf per hectare in this study was greater than that recorded by Brown et al. (2006) (3.1 t DM/ha). This difference is most likely the effect of variation in leaf drop as a result of variable growing conditions, variation between cultivars and the exclusion of petiole. There was some evidence that at moderate yields (10 t DM/ha) giant-type kales held less leaf as a proportion of the total compared with the intermediate stem type. This is consistent with the recent switch in breeding objectives to more leafy type kales.

The decrease in forage quality from the top to the bottom of kale stems has been noted previously (Stephen 1976). These data indicate that stems of giant types are lower quality than the intermediate-stem type at comparable quartiles on the stem. The impact on diet ME is predicted to be significant (Table 1). Greater quality for diets of intermediate stem kale compared with giant types would be predicted when grazing to a common residual. Higher residuals would need to be left on giant types in order that diet ME was equal to that of intermediate-stem kale. Potential differences may also exist within a cultivar due to variation in sowing date, fertiliser input and environment.

In a practical sense, giant-type kales may better fit a system where cow maintenance is the expectation particularly when the aim is to limit the amount of lower stem remaining after grazing. Intermediate-stem cultivars, in addition to being used for maintenance, may be more successful when increased cow condition is the objective. These data also highlight the need for grazing management guidelines which are kale-cultivar specific and these are currently underway.

\section{Utilisation}

Utilisation rates in feeding tables are often quoted to be around $70 \%$ although little field data are actually reported. Utilisation rates in this study were generally high with a mean of $80 \%$ (Fig. 3). Good weather and soil conditions leading up to the measurement period are likely to have been a factor in this. Wet and muddy conditions might be expected to lead to lower rates of utilisation because any kale trampled would most likely become unpalatable or unable to be eaten.

The observation that crop yield, dry matter percentage or break shape had no significant effect on utilisation suggests other factors such as daily kale allowance and the amount of other feeds offered are more important. Although it might appear logical that break dimensions and shape would have an effect on utilisation through reduced trampling, the data from this survey does not support this. While long narrow breaks may tend to increase rates of utilisation, other factors such as total daily allowance may be more important in this environment. However it is important to acknowledge that break width may become important under wet conditions. For example, long, thin breaks are often used to increase utilisation under wet soil conditions.

There was a clear relationship between daily kale allowance and the estimated daily kale intake of dairy cows (Fig. 4). High daily intakes of kale (10-12 kg DM/ cow/day) were achieved where high daily allowances (13$15 \mathrm{~kg} \mathrm{DM} / \mathrm{cow} /$ day) were offered. In these cases, utilisation was generally moderate $70-80 \%$ (Fig. 5). Utilisation rates of $90 \%$ and greater were generally associated with low total intakes although there were some exceptions. As a consequence high utilisation $(>90 \%)$ of kale could lead to poor outcomes in terms of body condition change. This observation suggests that the residual left after grazing can be a useful guide in determining whether cows are achieving their target intake.

\section{Allocation}

There were some large discrepancies between daily kale intakes measured and those indicated by the farmers (Fig. 6). A majority of dairy cows appeared to be eating considerably less kale than targeted. This discrepancy may reflect the vagaries of crop yield assessment and variations through the paddock. The area measured and reported in this survey may not have been representative of the whole paddock and, if lower, would have been recorded as an underfeeding event. The yield and utilisation measurement techniques employed are not without error and small discrepancies should be expected.

However, because utilisation was generally high and yield assessments generally accurate, low kale intakes were probably a result of poor allocation - getting the break size right. It should not be assumed that all cows missing their targeted kale intake are being underfed as in many situations kale is not the sole component of the 
diet and they may simply compensate for low kale intakes by eating more silage, hay or concentrates. However, underfeeding is a likely consequence where cows are not given the opportunity to increase intake of other dietary components.

\section{Summary}

Where changes in body condition of cows grazing kale are not meeting farmers' expectations there could be a number of causes. This survey has highlighted that daily kale intake even in dry Canterbury conditions is generally lower than estimated by farmers probably due to issues associated with allocation. This study has highlighted cultivar-specific effects on yield and leaf:stem ratios and quality. It also suggests there should be cultivar-specific grazing residual recommendations to achieve desired cow body condition outcomes.

\section{REFERENCES}

Beare, M.; White, S.; Wilson, D. 2006 Managing winter forages sustainably. pp. 231-244. In: Proceedings of the South Island Dairy Event, Invercargill.
Brown, H.E.; Maley, S.; Wilson, D.R. 2007. Investigations of alternative kale management: Production, regrowth and quality from different sowing and defoliation dates. Proceedings of the New Zealand Grassland Association 69: 29-33.

Burke, C.R.; Roche, J.R.; Aspin, P.W.; Lee J.M.; Taufa, V.K. 2005. Effect of pre- and postpartum pasture feeding intakes on postpartum anoestrous intervals in dairy cows. Proceedings of the New Zealand Society of Animal Production 65: 221-224.

Gowers, S.; Armstrong, S.D. 1994. A comparison of the yield and utilisation of six kale cultivars. New Zealand Journal of Agricultural Research 37: 481485.

Holmes, C.W.; Brookes I.M.; Garrick D.J.; Mackenzie, D.D.S.; Parkinson, T.J.; Wilson, G.F. 2002. Milk Production from Pasture. Butterworth NZ. Pp 302303.

Stephen, R.C. 1976. Effect of sowing and harvest dates of the leaf and stem yields of marrow-stem kale in relation to feed quality. Proceedings of the Agronomy Society of New Zealand 6: 43-48. 